\title{
Desenvolvimento social na Amazômia Ocidental: uma análise a partir dos munícipios do estado Acre
}

\author{
Social development in the western Amazon: an analysis from the municipalities of the \\ state of Acre
}

\author{
Catharine Neves Fernandes', Francisco Dietima da Silva Bezerra"
}

\begin{abstract}
Resumo
O objetivo do presente trabalho consiste em aferir o nível de desenvolvimento social dos municípios do Estado do Acre no período entre 2000 e 2010. Para tanto, foi criado o Índice de Desenvolvimento Social do Acre (IDSA), composto pelas dimensões habitação, renda, trabalho, saúde e segurança, e educação. Por meio da análise de componentes principais ficou constatado que somente cinco municípios apresentaram breve melhoria no IDSA, sendo fortemente influenciada pela dimensão saúde, reflexo da queda na taxa de mortalidade infantil. Já a dimensão habitação apresentou o pior desempenho, demonstrando a necessidade de políticas mais efetivas no Estado no sentido de melhorar as condições habitacionais dos domicílios.
\end{abstract}

Palavras-chave: Desenvolvimento Social; Componentes Principais; Estado do Acre

\begin{abstract}
The objective of the present study is to measure the level of social development of the municipalities of the State of Acre between 2000 and 2010. For this purpose, was created the Social Development Index of Acre (IDSA), composite by habitation, income, work, health and safety, and education. By of the analysis of main components, it was verified that only five municipalities demonstrate a brief improvement in the IDSA, being strongly influenced by the health dimension, reflex the decrease in the rate infant mortality. On the other hand, the housing dimension presented the worst performance, demonstrating the need for more effective policies in the State to improve housing conditions
\end{abstract}

Keywords: Social Development; Main Components; State of Acre

\footnotetext{
I Especialista em Direito Tributário e MBA em Gestão Tributária - francisco.bezerra@ifac.edu.br

II Professor do Instituto Federal do Acre - dietimabezerra@yahoo.com.br
} 


\section{Introdução}

Por muito tempo, as nações direcionavam seus esforços em ações que visavam unicamente atingir altos índices de crescimento econômico, de modo que o conceito de desenvolvimento estava ligado ao crescimento econômico. Em outras palavras, a concepção existente à época perfazia o pensamento de que o desenvolvimento seria alcançado à medida que a economia apresentasse elevados níveis de crescimento, o que levaria de forma automática a melhoria de indicadores sociais (SACHS, 2004).

Todavia, com o passar dos anos notou-se que o crescimento econômico não se traduzia necessariamente em melhoria da qualidade de vida da população. Nesse sentido, fez-se necessário que o desenvolvimento fosse medido e avaliado, também, por meio de indicadores capazes de aferi-lo em seus aspectos sociais, não somente em sua dimensão econômica. Assim, com a criação do Índice de Desenvolvimento Humano (IDH) nos anos de 1990, indicadores como educação e saúde ganharam importância na análise do desenvolvimento, ficando para trás a visão limitada em que pese o desenvolvimento ser medido tão somente pelo crescimento da renda per capita de um determinado país (VEIGA, 2005).

A partir de então, atribui-se aos indicadores sociais a função de mensurar o progresso social de uma dada região em suas mais diversas variáveis, apresentando-se como instrumento preponderante e indispensável. Dessa forma, Jannuzzi (2004, p. 15) os define como "um instrumento operacional para monitoramento da realidade social para fins de formulação e reformulação de políticas públicas”.

Diante disso, o presente trabalho objetiva aferir o nível de desenvolvimento social dos 22 municípios do Estado do Acre, no período de 2000 a 2010. Para tanto, será criado o Índice de Desenvolvimento Social do Acre (IDSA), considerando as dimensões habitação, renda, trabalho, saúde e segurança e educação, a partir da aplicação da análise de componentes principais. Cabe destacar que a população total do Estado em 2010, conforme o Instituto Brasileiro de Geografia e Estatística (IBGE), era de 733.559 mil habitantes, e PIB per capita de R\$14.733,50.

O trabalho encontra-se dividido em quatro seções, para além desta breve introdução. Na segunda seção são apresentadas as vias de desenvolvimento presente na literatura, buscando demonstrar que ainda não há um consenso sobre a utilização desse termo. Em sequência, a terceira seção discorre sobre os procedimentos metodológicos adotados. E seguida (quarta seção) são apresentados os resultados da pesquisa. E por fim, são dispostas as conclusões do trabalho.

\section{Desenvolvimento: aspectos teóricos}

Ao longo dos últimos anos, o conceito de desenvolvimento sofreu diversas reformulações dado o seu caráter multidimensional e a sua alta complexidade. Apesar de remontar aos primórdios da Ciência Econômica, a discussão em torno do desenvolvimento intensificou-se principalmente no pós-Segunda Guerra Mundial, cuja necessidade de reconstrução das nações destruídas pela guerra tornou-se iminente (RIBEIRO, 2004). Dentre as diferentes correntes de pensamento que buscam definir o desenvolvimento, a literatura econômica assegura que existem pelo menos três tipos: duas delas - como crescimento econômico e como mito - são mais comumente divulgadas, tendo em vista o seu simplismo exacerbado. Já a terceira via que busca conceituar o desenvolvimento como expansão das liberdades substantivas, torna-se bastante complexa de ser mensurada, o que, em muitos casos, acaba sendo um caminho espinhoso a ser trilhado (VEIGA, 2005, SEN, 2000).

Uma primeira concepção que busca conceituar o desenvolvimento, defende a ideia de que este é sinônimo de crescimento econômico, de modo que o mesmo viria natural e automaticamente a partir do momento em que as nações se tornassem ricas, dotadas de razoável capacidade científico-tecnológica. Para os chamados fundamentalistas de mercado, defensores dessa corrente cética de pensamento, o desenvolvimento seria uma decorrência natural do crescimento econômico em razão do que se chama de “efeito cascata” (SACHS, 2004; VEIGA, 2005).

De acordo com Soares Júnior e Quintella (2008), alguns dos maiores expoentes dessa corrente de pensamento, asseguram que o crescimento econômico soluciona de forma espontânea a pobreza, a miséria e as desigualdades sociais que assolam as diversas regiões e nações do planeta. Em outras palavras, acreditava-se "cegamente" que o crescimento das economias, medido em termos de renda per capita, asseguraria a abundância de bens e serviços necessários ao atendimento das necessidades dos mais pobres. Porém, na prática isso não ocorre, dados os elevados níveis de concentração da renda e pobreza em todo o mundo.

Segundo Veiga (2005), essa concepção tornou-se bastante aceita pelo fato de que até 1960 as únicas nações desenvolvidas eram justamente aquelas que haviam se tornado ricas pela industrialização, enquanto os países pobres eram aqueles nos quais os processos de industrialização eram incipientes ou ainda nem haviam começado. Todavia, ainda em 1950, já havia se tornado claro e evidente que o pensamento apregoado pelos fundamentalistas de mercado tornava-se cada vez mais improvável, tendo em vista que o intenso crescimento econômico vivenciado 
por alguns países semi-industrializados, dentre eles o Brasil, não havia proporcionado melhoria dos indicadores econômicos e sociais.

Para que haja desenvolvimento é imprescindível que o crescimento econômico seja utilizado como meio para ampliação das capacidades humanas, entendidas como o conjunto das coisas que as pessoas podem ser e/ou fazer na vida. As mais elementares são quatro: ter uma vida longa e saudável, ser instruído, ter acesso aos recursos necessários a um nível de vida digno e ser capaz de participar da vida da comunidade. $\mathrm{Na}$ ausência destas quatro, estarão indisponíveis todas as outras possíveis escolhas e muitas oportunidades na vida permanecerão inacessíveis. Além disso, há um fundamental pré-requisito que precisa ser explicitado: as pessoas têm que ser livres para que suas escolhas possam ser exercidas, para que garantam seus direitos e se envolvam nas decisões que afetarão suas vidas (SEN, 2000 VEIGA, 2005).

Nesse sentido, a utilização da renda per capita como indicador de desenvolvimento, passou a ser questionada a partir de 1990, com a publicação do relatório de desenvolvimento humano pelo Programa das Nações Unidas para o Desenvolvimento (PNUD), que mostrou o enorme abismo existente entre as diversas nações, principalmente no que se refere o acesso aos bens necessários à qualidade de vida da população. A partir de então, dada a limitação do PIB per capita na mensuração das reais condições de vida das pessoas, e na impossibilidade de criação de um indicador sintético capaz de medir todas as dimensões do desenvolvimento, a saída encontrada foi contemplar as três mais elementares capacidades humanas: educação, longevidade e renda. Mesmo assim, dada a complexidade e multidimensionalidade do desenvolvimento, o PNUD admite a limitação do IDH, já que este resulta da média aritmética da renda, educação e longevidade (VEIGA, 2005).

Diante da limitação apresentada por esse indicador na mensuração das diversas outras dimensões do desenvolvimento - cívica, cultural e ambiental -, Veiga $(2005 ; 2015)$ propõe que os governantes adotem outros índices complementares. Como exemplo, o autor reafirma a necessidade de se definir medidas que favoreçam a incorporação da dimensão ambiental a esse processo, já que não basta que haja apenas desenvolvimento, mas que este seja "sustentável”. Assim, a questão da sustentabilidade é uma discussão que está presente nos documentos internacionais desde a década de 1980, com a publicação do Relatório Brundtland, consagrada na Rio-92, e reafirmada na Rio+10 ocorrida em Johannesburgo. Portanto, esta é uma discussão que não é nada incipiente, necessitando que seja incorporada na questão da mensuração do desenvolvimento.

Segundo Veiga (2005, p. 17), uma segunda corrente de pensamento trata o desenvolvimento "como ficção, mito, ilusão, crença ou manipulação ideológica”, já que seria impossível as nações subdesenvolvidas alcançarem os mesmos padrões de desenvolvimento das nações industrializadas. Para os defensores dessa corrente de pensamento, chamados de pós-modernos, o termo desenvolvimento foi criado tão somente com o intuito de favorecer os países ricos no acúmulo cada vez maior de riquezas, enquanto que as nações pobres permaneciam em situação cada vez mais degradante, onde a pobreza e a miséria são frequentes. Sachs (2004, p. 26) afirma que para os pós-modernistas "o desenvolvimento funciona como uma armadilha ideológica construída para perpetuar as relações assimétricas entre as minorias dominadoras e as maiorias dominadas, dentro de cada país e entre países".

A ilusão do desenvolvimento baseia-se no fato de que existe uma reduzida possibilidade, ou quase nula, de os países periféricos ascenderem na rígida hierarquia capitalista mundial, formada por um pequeno grupo de países desenvolvidos e industrializados, e uma extensa periferia e "semiperiferia" compostas pelas nações pobres ou em desenvolvimento, respectivamente. De acordo com Veiga (2005), Arrighi, célebre defensor dessa ideia, afirma que o conceito de desenvolvimento como mito baseia-se no fato de que a riqueza das nações desenvolvidas não pode ser generalizada, já que a lógica do sistema capitalista se baseia em relações de exploração e exclusão que pressupõe a reprodução contínua da pobreza da maioria da população mundial. É interessante notar que ao se utilizar do Produto Nacional Bruto (PNB) per capita para demonstrar que poucas foram as nações que ascenderam na rígida hierarquia da economia capitalista, Arrighi continua a insistir na confusão entre crescimento econômico e desenvolvimento defendida pela visão convencional.

Essa ideia de desenvolvimento é apresentada de forma mais consiste e persuasiva por outros defensores dessa corrente, como o diplomata peruano Oswaldo de Rivero, o diplomata iraniano Majid Rahnema, e o acadêmico suíço Gilbert Rist. Conforme Veiga (2005), a análise de Oswald de Rivero fundamenta-se na configuração de que o poder econômico-global no contexto atual não é mais ditado apenas pelo poder das grandes potências, mas sim pela presença de uma burguesia capaz de promover as mudanças técnico-científicas nesses países.

Nesse sentido, o subdesenvolvimento de muitos países é fruto da combinação entre a miséria cientifico-tecnológica e o explosivo crescimento demográfico urbano. Isto ocorre, em grande parte, devido os países em desenvolvimento exportarem produtos de baixo valor agregado, o que reflete na baixa geração de receitas para investimentos em setores prioritários para amenização das desigualdades e mazelas sociais (VEIGA, 2005).

Segundo Ribeiro (2004), as fundamentações de Gilbert Rist e Majid Rahnema quanto a ideia de desenvolvimento como mito são semelhantes. De modo geral, ambos defendem que o desenvolvimento não passa de manipulação ideológica criada pelas nações desenvolvidas, com o intuito de manter sobre seu domínio as suas ex-colônias e, 
assim, explorar seus recursos naturais e as utilizar como mercados necessários à sua expansão econômica.

Há ainda o mito do desenvolvimento baseado nas ideias de Furtado que, em síntese, refere-se à impossibilidade de universalização dos padrões de consumo das nações desenvolvidas às grandes massas populacionais, que formam uma extensa periferia mundial. Segundo Furtado (1974, p. 16), “a ideia de universalização do desenvolvimento das nações industrializadas se constitui uma prolongação do mito do progresso, elemento essencial na ideologia diretora da revolução burguesa, dentro da qual se criou a atual sociedade industrial”. Em outras palavras, a possibilidade de ascensão seria a negação da especificidade do subdesenvolvimento, onde todos poderiam ascender na rígida hierarquia da economia mundial capitalista, o que de fato não é verdade.

Uma terceira via que busca explicar o desenvolvimento foi concebida de forma mais sistemática e clara pelo indiano Amartya Sen (2000). Para o autor, o termo desenvolvimento vai além do crescimento do PNB per capita, do aumento de renda, da industrialização e progresso tecnológico. Para que haja desenvolvimento, antes de mais nada, deve haver expansão das liberdades humanas, o que significa romper com todas as fontes de privações que impedem as pessoas de terem suas escolhas. Não obstante, Sen reconhece que o crescimento da renda per capita pode ser muito importante para a expansão dessas liberdades, mas estas dependem de outros determinantes, como geração de emprego, serviços de educação, saúde, segurança pública, saneamento básico, etc., além da oportunidade de participação nas discussões políticas e sociais (SEN, 2000).

Conforme Souza (2008), o conceito de desenvolvimento difundido por Amartya Sen rompe com as vertentes teóricas que defendem o desenvolvimento como sinônimo de crescimento. Segundo o autor, Sen parte de uma perspectiva muito mais ampla, afirmando que é necessário que haja melhoria da qualidade de vida dos indivíduos para que haja desenvolvimento. Segundo Sen (2000), liberdades instrumentais dizem respeito aos direitos e oportunidades que permitem a expansão das liberdades individuais. Liberdades substantivas estão ligadas aos direitos humanos de alimentação, moradia, educação, liberdade de expressão, saúde e participação política.

Nota-se que essas ideias contrastam com a tese propagada pelos defensores do desenvolvimento como crescimento econômico e sua visão quantitativa de mundo, pois, para estes, o crescimento da riqueza medida em termos de renda per capita é o fim último a ser alcançado para a noção de desenvolvimento como liberdade, o crescimento é apenas um dos meios de se alcançar o tão almejado desenvolvimento. Em síntese, a contribuição fundamental do pensamento de Sen é demonstrar que não existe uma relação linear causal entre crescimento econômico e desenvolvimento, como pensam e defendem os economistas ortodoxos (SEN, 2000).

\section{Metodologia}

Para alcançar o objetivo proposto no presente trabalho, concernente à aferição do nível de desenvolvimento social dos municípios do Estado do Acre, no período de 2000 e 2010, foi adotado o método da Análise de Componentes Principais para criação do Índice de Desenvolvimento Social do Acre (IDSA).

Partindo desse pressuposto, para criação do IDSA foi utilizado o método de Análise de Componentes Principais, buscando sintetizar as informações acerca de 28 indicadores incorporados em cinco dimensões, as quais influenciam diretamente o desenvolvimento humano nestes municípios. As demonstrações referentes ao IDSA foram realizadas, considerando que quanto maior for o valor do índice, consequentemente, maior/melhor será o nível de desenvolvimento dos municípios.

\section{Análise de Componentes Principais}

A análise de componentes principais é um método estatístico de análise multivariada, cujo objetivo básico é o de construir um conjunto de variáveis $\mathrm{X}_{1}, \mathrm{X}_{2}, \ldots, \mathrm{X}_{\mathrm{K}}$, ortogonais (estatisticamente independentes), a partir de uma transformação linear operada em um dado conjunto de variáveis observadas. A respeito desse método de análise multivariada, Mingoti (2007, p 59) afirma que:

Seu objetivo principal é o de explicar a estrutura de variância e covariância de um vetor aleatório, composto de p-variáveis aleatórias, através da construção de combinações lineares das variáveis originais. Estas combinações lineares são chamadas de componentes principais e são não correlacionadas entre si.

Pode-se afirmar que a finalidade do método encontra-se na redução da complexidade de um conjunto de dados, de maneira que os componentes principais captem o máximo de variação total dos mesmos. Conforme dispõe Rosado, Rossato e Lima (2009), o processo de estimação é tal que o primeiro CP capta o máximo de variação possível, o segundo capta o máximo possível do restante da variância e assim sucessivamente, preservando, portanto, as informações mais significantes.

Ou seja, o método é empregado para criar variáveis que, por construção, apresentam correlação igual ao zero, ou seja, satisfazem a hipótese de independência das variáveis explicativas do método de regressão linear, ou seja, 
da inexistência de multicolinearidade entre estas variáveis. Em análise regional e urbana, o método tem sido empregado com uma finalidade classificatória de regiões ou de cidades, por meio da criação de um índice que permite a hierarquização das mesmas.

Assim, seja $\mathrm{X}=\left[\begin{array}{lllll}\mathrm{X}_{1} & \mathrm{X}_{2} & \mathrm{X}_{3} & \ldots & \mathrm{X}_{\mathrm{p}}\end{array}\right]$ um vetor de $\mathrm{p}$ variáveis com matriz de variâncias e covariâncias $\Sigma$,

$$
\operatorname{Var}-\operatorname{Cov}(\mathrm{X})=\sum_{\text {pхр }}
$$

Dessa forma, os CP's (componentes principais) são combinações lineares dos X's, da seguinte forma (PEREIRA, et.al, 2016):

$$
\begin{aligned}
& Y_{1}=e_{11}^{\prime} x=e_{11}^{\prime} x_{1}+e_{12}^{\prime} x_{2}+e_{1 p}^{\prime} x_{p} \\
& Y_{2}=e_{2}^{\prime} x=e_{21}^{\prime} x_{1}+e_{22}^{\prime} x_{2}+e^{\prime}{ }_{2 p} x_{p} \\
& Y_{p}=e_{p}^{\prime} x=e_{p 1}^{\prime} x_{1}+e_{p 2}^{\prime} x_{2}+e_{p p}^{\prime} x_{p}
\end{aligned}
$$

O Índice de Desenvolvimento Social do Acre (IDSA) se apresenta como um indicador sintético, criado a partir de uma matriz de covariância oriunda do Indicador Social de Desenvolvimento dos Municípios (ISDM, 2000 e 2010), posteriormente submetida à análise de componentes principais.

É importante destacar que para evitar coeficientes negativos que prejudiquem a formação do IDSA, torna-se necessário inserir todos os valores das componentes principais no primeiro quadrante, conforme transformação a seguir:

$$
C P_{i j}=\frac{\left(C P_{i j}-C P_{i}^{\text {min }}\right)}{\left(C P_{i}^{\text {max }}-C P_{i}^{\text {min }}\right)}
$$

Em que:

CPmin = Mínimo observado para o j-ésimo escore do componente principal associado ao i-ésimo;

CPmax = Máximo observado para o j-ésimo escore do componente principal associado ao i-ésimo.

Na construção do Índice de Desenvolvimento Econômico (IDSEi), associado ao i-ésimo município, definiu-se a equação:

$$
I S D E=\frac{\lambda_{i}}{\sum_{i=1}^{n} \lambda_{i}} C P_{i j}
$$

Em que:

IDSE = é o índice do $i$ - ésimo município;

= a j-ésimo raiz característica;

$\mathrm{n}=\mathrm{o}$ número de componentes utilizados na análise;

$\mathrm{CP}_{\mathrm{ij}}=$ o j-ésimo escore do componente do i-ésimo município;

$\Sigma$ o somatório das raízes características referentes aos n componentes extraídos.

Isso possibilitará aferir o nível do desenvolvimento social nos Municípios do Estado do Acre, ocorrido no período de 2000 e 2010, por meio das variáveis Habitação $\left(X_{1}\right)$, Renda $\left(X_{2}\right)$, Trabalho $\left(X_{3}\right)$, Saúde e Segurança $\left(X_{4}\right)$ e Educação $\left(\mathrm{X}_{5}\right)$, descritas no quadro 1: 
Quadro 1 - Descrição das dimensões utilizadas na criação do IDSA

\begin{tabular}{|c|c|}
\hline Dimensões & Descriçãa \\
\hline Habitação (X1) & $\begin{array}{l}\text { Coleta de lixo, energia elétrica, água canalizada, } \\
\text { esgotamento sanitário, domicílio próprio e densidade } \\
\text { de moradores por cômodo; }\end{array}$ \\
\hline Renda (X2) & Extrema pobreza e pobreza; \\
\hline Trabalho (X3) & $\begin{array}{l}\text { Taxa de ocupação, taxa de formalização e taxa de } \\
\text { trabalho infantil; }\end{array}$ \\
\hline Saúde e segurança (X4) & $\begin{array}{c}\text { Taxa de mortalidade infantil, mortalidade infantil } \\
\text { por causas evitáveis, nascidos vivos com baixo peso } \\
\text { ao nascer, gravidez precoce, mortalidade por causas } \\
\text { evitáveis e Segurança (taxa de homicídio). }\end{array}$ \\
\hline Educação (X5) & $\begin{array}{l}\text { Frequência escolar, Taxa de analfabetismo, adequação } \\
\text { idade/série e nota da prova Brasil (ensino infantil, } \\
\text { fundamental, médio e geral). }\end{array}$ \\
\hline
\end{tabular}

Fonte: Souza, et al. (2012)

Para tanto, com a utilização do Programa SPSS no processo de obtenção dos Componentes Principais, após transformação dos dados, foi demonstrado o percentual de variância explicada por cada componente, acerca das dimensões analisadas. Conseguinte, foram extraídos os componentes principais CP1 e CP2 para os anos 2000 e 2010 , considerando que estes apresentam raízes características maiores que " 1 ", o que denota que eles por si só, possuem quantidade suficiente de informação para compor com o Índice de Desenvolvimento Social do Acre (IDSA).

\section{Fonte de dados}

A fonte de dados utilizada neste trabalho, para criação do IDSA, foi o Indicador Social de Desenvolvimento dos Municípios (ISDM) elaborado pela Fundação Getúlio Vargas (FGV), a partir de 28 indicadores incorporados nas dimensões Habitação, Renda, Trabalho, Saúde/Segurança e Educação (SOUZA, et al., 2012).

\section{Resultados e Discussões}

Inicialmente, buscando identificar a adequabilidade da amostra para a aplicação da análise de componentes principais foi realizado o teste de Barllet, cujo o objetivo é constatar a presença de correlações entre as variáveis. Como resultado obteve-se um valor de 0,780 , levando a rejeição da hipótese nula de que as variáveis estão correlacionadas. Logo, se as variáveis não estão correlacionadas, torna-se possível a análise por meio da técnica de componentes principais.

Pode-se afirmar que o método de componentes principais visa reduzir o conjunto de dados que se busca analisar. Assim, percebe-se pela tabela 1 que os componentes CP1 e CP2 são os únicos a apresentarem raiz característica maior do que 1, tanto em 2000 quanto em 2010, significando que esses dois componentes são suficientes para explicar, em média, $84,05 \%$ da variabilidade acumulada das cinco dimensões que compõem o índice de desenvolvimento social dos municípios do Estado do Acre. 
Tabela 1- Variância explicada pelos Componentes Principais (\%)

\begin{tabular}{lccc}
\hline $\begin{array}{l}\text { Componente } \\
\text { Principal }\end{array}$ & Raiz Característica & \% Variância captada pelo CP & \% Variância Acumulada \\
\hline \multicolumn{3}{l}{ (ano 2000) } \\
\hline CP1 & 2,97 & 59,41 & 59,40 \\
CP2 & 1,26 & 25,15 & 84,55 \\
CP3 & 0,50 & 9,95 & 94,50 \\
CP4 & 0,17 & 3,35 & 97,86 \\
CP4 & 0,11 & 2,14 & 100,00 \\
\hline & & & 59,41 \\
CP1 & ano 2010) & 83,55 \\
CP2 & 3,11 & 62,19 & 95,48 \\
CP3 & 1,07 & 21,36 & 98,52 \\
CP4 & 0,59 & 11,93 & 100,00 \\
CP5 & 0,15 & 3,05 & 1,48 \\
\hline
\end{tabular}

Fonte: Resultados de Pesquisa

A tabela 2 mostra as cargas fatoriais estimadas após a rotação ortogonal pelo método varimax ${ }^{1}$, destacando-se que as maiores cargas fatorais correspondentes são aquelas que têm relação positiva com as dimensões analisadas. Nesse sentido, percebe-se que o CP1 está relacionado positivamente com habitação, renda e educação, tanto em 2000 quanto em 2010. Por outro lado, o CP2 atesta uma relação positiva, em ambos os anos, apenas com saúde e segurança, e com trabalho apenas em 2000. De modo geral, isso significa que boas condições habitacionais (coleta de lixo, esgotamento sanitário, água canalizada, etc), renda suficiente para redução da pobreza, escolaridade elevada, melhores condições de acesso ao trabalho, saúde e segurança tendem a favorecer o desenvolvimento de uma determinada região. Dessa forma, políticas públicas que favoreçam a melhoria desses indicadores são primordiais para se alcançar níveis satisfatórios de bem-estar social da população.

Tabela 2 - Correlação dos Componentes Principais com as variáveis

\begin{tabular}{lcc}
\hline \multicolumn{1}{c}{ Variáveis } & CP1 & CP2 \\
\hline Habitação $\left(\mathrm{X}_{1}\right)$ & (ano 2000) & 0,292 \\
Renda $\left(\mathrm{X}_{2}\right)$ & 0,850 & 0,113 \\
Trabalho $\left(\mathrm{X}_{3}\right)$ & 0,953 & 0,900 \\
Saúde e Segurança $\left(\mathrm{X}_{4}\right)$ & $-0,173$ & 0,562 \\
Educação $\left(\mathrm{X}_{5}\right)$ & $-0,661$ & 0,184 \\
\hline & 0,934 & \\
\hline Habitação $\left(\mathrm{X}_{1}\right)$ & $($ ano 2010$)$ & $-0,097$ \\
Renda $\left(\mathrm{X}_{2}\right)$ & 0,967 & $-0,141$ \\
Trabalho $\left(\mathrm{X}_{3}\right)$ & 0,922 & 0,356 \\
Saúde e Segurança $\left(\mathrm{X}_{4}\right)$ & 0,684 & 0,942 \\
Educação $\left(\mathrm{X}_{5}\right)$ & 0,133 & $-0,159$ \\
\hline Fonte: Resultados de Pesquisa & 0,917 &
\end{tabular}

1 Minimiza o número de variáveis que têm altas cargas em um fator (FÁVERO, et al., 2009). 
Pela tabela 3 percebe-se que o Estado do Acre apresentou queda no seu IDSA, entre 2000 e 2010. Esse desempenho foi influenciado, sobretudo, pelas dimensões trabalho, saúde e segurança, além da renda que apresentaram variação negativa no período analisado, conforme será mostrado posteriormente (tabela 5).

Tabela 3: Componentes Principais e variação do IDSA - 2000 e 2010

\begin{tabular}{|c|c|c|c|c|c|c|c|}
\hline \multirow[t]{2}{*}{ Municípios } & \multicolumn{3}{|c|}{2000} & \multicolumn{3}{|c|}{2010} & \multirow{2}{*}{$\begin{array}{c}\text { Variação IDSA } \\
(\%)\end{array}$} \\
\hline & CP1 & CP2 & IDSA & CP1 & CP2 & IDSA & \\
\hline Acre & 0,55 & 0,47 & 52,41 & 0,45 & 0,43 & 44,58 & $-14,93$ \\
\hline Acrelândia & 0,63 & 0,24 & 51,32 & 0,58 & 0,22 & 48,67 & $-5,16$ \\
\hline Assis Brasil & 0,75 & 0,24 & 59,70 & 0,48 & 0,37 & 45,33 & $-24,07$ \\
\hline Brasiléia & 0,70 & 0,48 & 63,20 & 0,61 & 0,25 & 51,82 & $-18,01$ \\
\hline Bujari & 0,63 & 0,14 & 48,47 & 0,59 & 0,56 & 58,57 & 20,84 \\
\hline Capixaba & 0,58 & 0,00 & 40,57 & 0,47 & 0,29 & 42,09 & 3,75 \\
\hline Cruzeiro do Sul & 0,67 & 0,59 & 64,95 & 0,68 & 0,43 & 61,80 & $-4,85$ \\
\hline Epitaciolândia & 0,74 & 0,34 & 62,36 & 0,67 & 0,29 & 57,60 & $-7,63$ \\
\hline Feijó & 0,39 & 0,07 & 29,15 & 0,21 & 0,58 & 30,33 & 4,05 \\
\hline Jordão & 0,00 & 0,62 & 18,44 & 0,10 & 0,66 & 24,10 & 30,69 \\
\hline Mâncio Lima & 0,53 & 0,57 & 54,10 & 0,48 & 0,00 & 35,86 & $-33,72$ \\
\hline Manoel Urbano & 0,44 & 0,22 & 37,42 & 0,36 & 0,19 & 31,51 & $-15,79$ \\
\hline Marechal Thaumaturgo & 0,30 & 0,44 & 33,90 & 0,03 & 0,39 & 12,12 & $-64,25$ \\
\hline Plácido de Castro & 0,65 & 0,64 & 64,41 & 0,65 & 0,55 & 62,30 & $-3,28$ \\
\hline Porto Acre & 0,66 & 0,51 & 61,59 & 0,54 & 0,53 & 53,67 & $-12,86$ \\
\hline Porto Walter & 0,35 & 0,98 & 54,12 & 0,05 & 0,23 & 9,92 & $-81,67$ \\
\hline Rio Branco & 1,00 & 0,85 & 95,65 & 1,00 & 0,53 & 87,99 & $-8,01$ \\
\hline Rodrigues Alves & 0,27 & 1,00 & 48,37 & 0,21 & 0,37 & 25,35 & $-47,59$ \\
\hline Santa Rosa do Purus & 0,25 & 0,17 & 22,50 & 0,00 & 0,83 & 21,21 & $-5,73$ \\
\hline Sena Madureira & 0,61 & 0,34 & 52,79 & 0,51 & 0,31 & 45,57 & $-13,68$ \\
\hline Senador Guiomard & 0,76 & 0,70 & 74,00 & 0,80 & 1,00 & 84,90 & 14,73 \\
\hline Tarauacá & 0,50 & 0,47 & 48,98 & 0,27 & 0,56 & 34,75 & $-29,05$ \\
\hline Xapuri & 0,65 & 0,71 & 66,94 & 0,61 & 0,39 & 55,32 & $-17,36$ \\
\hline
\end{tabular}

Fonte: Resultados de Pesquisa

Percebe-se (tabela 3) que maioria dos municípios do Estado do Acre apresentaram variação negativa no nível de desenvolvimento social entre os anos de 2000 e 2010, com destaque para os municípios de Porto Walter (-81,67\%) e Marechal Thaumaturgo (-64,25\%), reflexo da evolução negativa de todos os indicadores (habitação, renda, trabalho, saúde e segurança, e educação). Somente Jordão (30,69\%), Bujari (20,84\%), Senador Guiomard (14,73\%) e Feijó $(4,05 \%)$ apresentaram breve crescimento, influenciando sua posição no ranking entre 2000-2010 no seu IDSA. Entre os componentes principais, percebe-se que o desenvolvimento de cada município é captado, em grande parte pelo $\mathrm{CP} 1$, o que corrobora os dados apresentados anteriormente (tabela 1).

Após realizar uma hierarquização dos municípios, considerando que quanto maior for o valor do índice maior/ melhor será o nível de desenvolvimento - consoante detalhado na metodologia -, nota-se através da tabela 4 , que os municípios mais bem posicionados (Rio Branco, Senador Guiomard, Cruzeiro do Sul e Plácido de Castro) no ranking são praticamente os mesmos no período analisado. Isso está relacionado ao melhor desempenho de algumas dimensões específicas para cada município, além do mais, Rio Branco e Cruzeiro do Sul, por serem as duas maiores 
cidades do Estado, são dotados de maior dinamismo econômico, o que incentiva os investimentos por parte do setor público e privado. No caso de Senador Guiomard e Plácido de Castro são localizados próximo à capital Rio Branco, o que lhes proporciona certos transbordamentos da dinâmica econômica e social desta.

Tabela 4: Hierarquização dos municípios em função do IDSA 2000 e 2010

\begin{tabular}{|c|c|c|c|c|c|}
\hline Ranking & Municípios & $\begin{array}{l}\text { IDSA } \\
(2000)\end{array}$ & Ranking & Municípios & $\begin{array}{l}\text { IDSA } \\
(2010)\end{array}$ \\
\hline $1^{o}$ & Rio Branco & 95,65 & $1^{\circ}$ & Rio Branco & 87,99 \\
\hline $2^{\mathbf{o}}$ & Senador Guiomard & 74,00 & $2^{\circ}$ & Senador Guiomard & 84,90 \\
\hline $3^{\circ}$ & Xapuri & 66,94 & $3^{\circ}$ & Plácido de Castro & 62,30 \\
\hline $4 \stackrel{\circ}{ }$ & Cruzeiro do Sul & 64,95 & $4 \stackrel{\circ}{ }$ & Cruzeiro do Sul & 61,80 \\
\hline $5 \stackrel{\circ}{ }$ & Plácido de Castro & 64,41 & $5 \stackrel{\circ}{-}$ & Bujari & 58,57 \\
\hline $6 \stackrel{0}{-1}$ & Brasiléia & 63,20 & $6^{\circ}$ & Epitaciolândia & 57,60 \\
\hline $7 \stackrel{\circ}{7}$ & Epitaciolândia & 62,36 & $7 \stackrel{\circ}{1}$ & Xapuri & 55,32 \\
\hline $8^{\circ}$ & Porto Acre & 61,59 & $8^{\circ}$ & Porto Acre & 53,67 \\
\hline 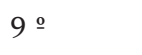 & Assis Brasil & 59,70 & $9 \stackrel{\circ}{1}$ & Brasiléia & 51,82 \\
\hline $10 \stackrel{\circ}{1}$ & Porto Walter & 54,12 & $10 \stackrel{\circ}{1}$ & Acrelândia & 48,67 \\
\hline $11 \stackrel{\circ}{1}$ & Mâncio Lima & 54,10 & $11 \stackrel{\circ}{1}$ & Sena Madureira & 45,57 \\
\hline $12 \stackrel{\circ}{2}$ & Sena Madureira & 52,79 & $12 \stackrel{\circ}{2}$ & Assis Brasil & 45,33 \\
\hline $13^{\circ}$ & Acrelândia & 51,32 & $13 \stackrel{\circ}{-1}$ & Capixaba & 42,09 \\
\hline $14^{\circ}$ & Tarauacá & 48,98 & $14^{\circ}$ & Mâncio Lima & 35,86 \\
\hline $15^{\circ}$ & Bujari & 48,47 & $15^{\circ}$ & Tarauacá & 34,75 \\
\hline $16^{\circ}$ & Rodrigues Alves & 48,37 & $16^{\circ}$ & Manoel Urbano & 31,51 \\
\hline $17 \stackrel{\circ}{ }$ & Capixaba & 40,57 & $17 \stackrel{\circ}{1}$ & Feijó & 30,33 \\
\hline $18 \stackrel{\circ}{2}$ & Manoel Urbano & 37,42 & $18 \stackrel{\circ}{-}$ & Rodrigues Alves & 25,35 \\
\hline 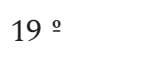 & Marechal Thaumaturgo & 33,90 & $19 \stackrel{-}{1}$ & Jordão & 24,10 \\
\hline $20 \stackrel{\circ}{2}$ & Feijó & 29,15 & $20 \stackrel{\circ}{2}$ & Santa Rosa do Purus & 21,21 \\
\hline $21^{\circ}$ & Santa Rosa do Purus & 22,50 & $21 \stackrel{\circ}{2}$ & Marechal Thaumaturgo & 12,12 \\
\hline $22 \stackrel{\circ}{-}$ & Jordão & 18,44 & $22 \stackrel{\circ}{-}$ & Porto Walter & 9,92 \\
\hline
\end{tabular}

Fonte: Resultados de Pesquisa

Quando se analisa a contribuição das dimensões separadamente na composição do IDSA, verifica-se pela tabela 5 que o desenvolvimento social do Acre é explicado em grande parte pela saúde e segurança. Conforme Souza et al. (2012), o Estado do Acre apresentou nesse período queda na taxa de mortalidade infantil, além de diminuição no percentual de mulheres entre 10 e 19 anos que tiveram filho. Em relação à dimensão trabalho com preponderância em ambos os períodos analisados, o autor afirma que a taxa de ocupação no Estado era superior à média nacional, seguida de uma taxa de trabalho infantil menor do que aquela observada no restante do país, o que contribui para um desempenho favorável quanto a essa dimensão. 
Tabela 5: Participação absoluta das dimensões na composição do IDSA - Acre

\begin{tabular}{|c|c|c|c|c|c|c|c|c|c|c|}
\hline \multirow{2}{*}{ Município } & \multicolumn{5}{|c|}{2000} & \multicolumn{5}{|c|}{2010} \\
\hline & $\mathbf{H}$ & $\mathbf{R}$ & $\mathbf{T}$ & $S$ & $\mathbf{E}$ & $\mathbf{H}$ & $\mathbf{R}$ & $\mathbf{T}$ & $S$ & $\mathbf{E}$ \\
\hline Acre & 2,78 & 3,52 & 4,75 & 5,27 & 2,52 & 2,64 & 3,05 & 3,87 & 4,6 & 2,57 \\
\hline Acrelândia & 2,68 & 4,02 & 3,68 & 5,34 & 3,3 & 3,15 & 3,67 & 3,81 & 3,47 & 3,71 \\
\hline Assis Brasil & 3,48 & 4,06 & 3,96 & 3,08 & 3,03 & 2,93 & 2,77 & 4,1 & 3,99 & 2,75 \\
\hline Brasiléia & 3,13 & 3,95 & 4,53 & 4,94 & 3,92 & 3,58 & 3,51 & 3,64 & 3,91 & 3,97 \\
\hline Bujari & 2,32 & 3,52 & 4,58 & 1,18 & 3,04 & 2,72 & 3,54 & 4,69 & 5,04 & 3,21 \\
\hline Capixaba & 2,37 & 4,03 & 3,5 & 3,46 & 1,82 & 2,49 & 3,82 & 3,56 & 3,94 & 2,8 \\
\hline Cruzeiro do Sul & 3,14 & 4,06 & 4,79 & 5,66 & 3,74 & 3,3 & 3,76 & 4,37 & 4,68 & 4,22 \\
\hline Epitaciolândia & 3,13 & 4,41 & 4,21 & 3,9 & 3,54 & 3,35 & 4,21 & 3,76 & 4,27 & 4,5 \\
\hline Feijó & 2,27 & 2,66 & 3,94 & 4,03 & 0,77 & 2,03 & 2,19 & 2,99 & 5,85 & 1,27 \\
\hline Jordão & 1,85 & 1,26 & 5,02 & 10,53 & $-0,46$ & 1,17 & 1,06 & 3,98 & 5,24 & 0,54 \\
\hline Mâncio Lima & 2,47 & 3,26 & 5,48 & 4,43 & 2,98 & 2,71 & 2,94 & 4,15 & 1,43 & 3,31 \\
\hline Manoel Urbano & 2,38 & 3,26 & 4,08 & 5,19 & 1,31 & 2,39 & 3,38 & 4,11 & 2,44 & 0,52 \\
\hline Marechal Thaumaturgo & 1,87 & 2,18 & 5,4 & 4,84 & 1,36 & 1,28 & 1,73 & 2,28 & 4,83 & 1,11 \\
\hline Plácido de Castro & 2,93 & 4,02 & 4,95 & 6,07 & 3,91 & 3,18 & 3,54 & 4,29 & 5,5 & 4,05 \\
\hline Porto Walter & 2,39 & 3,45 & 6,72 & 7,07 & 1 & 1,27 & 2,4 & 2,61 & 3,49 & 0,28 \\
\hline Rio Branco & 4,73 & 5,09 & 5,39 & 3,95 & 4,9 & 4,59 & 4,96 & 5,14 & 5,32 & 5,16 \\
\hline Rodrigues Alves & 2,27 & 2,78 & 6,32 & 9,23 & 1,44 & 2,16 & 1,52 & 3,13 & 4,29 & 2,12 \\
\hline Santa Rosa do Purus & 2,37 & 2,12 & 3,74 & 6,96 & $-0,01$ & 1,38 & 0,36 & 4,42 & 5,66 & $-1,85$ \\
\hline Senador Guiomard & 3,26 & 4,5 & 5,29 & 4,84 & 4,22 & 3,25 & 4,74 & 4,71 & 8,54 & 4,08 \\
\hline Sena Madureira & 2,75 & 3,55 & 4,5 & 3,96 & 3,04 & 2,84 & 3,58 & 3,67 & 4,05 & 3,07 \\
\hline Tarauacá & 2,78 & 3,03 & 4,75 & 5,59 & 2,44 & 2,11 & 2,31 & 3,49 & 5,42 & 1,48 \\
\hline Xapuri & 3,64 & 4,01 & 4,87 & 6,78 & 2,98 & 3,38 & 3,77 & 4,16 & 4,39 & 2,89 \\
\hline Porto Acre & 2,99 & 4,17 & 4,75 & 4,96 & 3,22 & 2,85 & 3,33 & 4 & 5,36 & 3,26 \\
\hline
\end{tabular}

Em relação às dimensões habitação e educação, nota-se que foram aquelas com menor participação, cujos valores apresentam-se bastante baixos quando comparados aos demais (tabela 5). Em relação à primeira dimensão, pode-se afirmar que os domicílios dos munícipios menores do Estado ainda sofrem com a falta de água canalizada, energia elétrica, coleta de lixo, etc., o que torna preocupante essa questão, tendo em vista que esses são indicadores relacionados ao controle de doenças e que afetam a qualidade de vida das pessoas. No tocante à educação, mesmo tendo havido aumento da participação dessa dimensão no período analisado, o Estado e seus munícipios apresentam um valor abaixo, o que pode estar relacionado à baixa taxa de frequência escolar das crianças de 0 a 4 anos, sobretudo em municípios menores que ainda carecem com a falta de creches, e à taxa de distorção idade-série que se mostra discrepante em relação à média nacional.

De modo geral, ficou evidenciado que os municípios com os melhores índices estão localizados próximos uns dos outros, ocorrendo o mesmo com aqueles cujos resultados são mais insatisfatórios. Como exemplo disso temos que os municípios com melhores resultados estão no entorno de Rio Branco (capital do Acre) - sendo aquele a apresentar o melhor IDSA em 2000 e 2010, e também o melhor IDH. Nessa perspectiva, os municípios cujos resultados foram baixos são justamente aqueles que estão muito distantes da capital, muitos deles ainda sofrem com o isolamento (Porto Walter, Marechal Thaumaturgo, Jordão, Santa Rosa do Purus) sendo possível o acesso às suas sedes municipais somente por meio fluvial e aéreo com aviões de pequeno porte.

\section{Considerações Finais}

A aplicabilidade de componentes principais demonstrou eficácia na síntese das variáveis estudadas e conseguinte favorecimento da análise realizada, em virtude da grande captação de variância e simplificação dos dados. 
Ficou constatado por meio da análise um nível de heterogeneidade entre os municípios acreanos, com vistas ao progresso social.

Em análise das variáveis restou comprovado que as dimensões Trabalho, Saúde e Segurança foram aquelas que mais colaboraram para o desenvolvimento social dos respectivos municípios no período apurado.

A análise demonstrou uma problemática generalizada em grande parte dos municípios do Estado do Acre no tocante ao desenvolvimento social, já que que somente 5 municípios apresentaram crescimento no IDSA entre 2000 e 2010. Em relação aos municípios do Acre, pode-se tirar alguns apontamentos gerais a partir das variáveis consideradas: A saúde e segurança se apresentaram como as principais dimensões a contribuírem para o desenvolvimento do Estado, apesar de terem apresentado queda, tendo participação, também, da dimensão trabalho. Alguns estudos demonstram que o Acre, nesse período, apresentou melhoras significativas nesses indicadores. No entanto, a piora em certos indicadores, a exemplo da habitação, acaba puxando o IDSA do Acre para baixo, ensejando a necessidade de políticas públicas que favoreçam a melhoria dos indicadores habitacionais.

Os dados mostram uma espacialidade muito heterogênea em relação às dimensões analisadas para o Estado do Acre no período de 2000 a 2010, conforme resultados da pesquisa. Percebe-se que no Estado do Acre as políticas implementadas nos municípios acreanos seguem um padrão unificado sem que as particularidades e problemáticas locais sejam consideradas, o que de certo modo, acaba por gerar resultados tão díspares e ineficientes entre os municípios do Estado, corroborando os resultados apontados.

Torna-se necessário uma investigação mais específica do conjunto de políticas públicas que estão sendo direcionadas a esses municípios, no sentido de identificar as maiores fragilidades de cada um deles e, assim, concentrar esforços para que o verdadeiro desenvolvimento seja alcançado, dando qualidade de vida à população.

\section{Referências}

FURTADO, C. O mito do desenvolvimento econômico. Rio de Janeiro: Paz e Terra, 1974.

IBGE. Instituto Brasileiro de Geografia e Estatística (IBGE). Censo Demográfico - 2010. Disponível em: www. ibge.gov.br. Acesso em: 10 Fev. 2018.

IBGE. Instituto Brasileiro de Geografia e Estatística (IBGE). Sistema de Contas Regionais (SCR) - 2010. Disponível em: www.ibge.gov.br. Acesso em: 10 Fev. 2018.

FÁVERO, L. P. L. et al. Análise de Dados: Modelagem Multivariada para Tomada de Decisões. 1. ed. Rio de Janeiro: Elsevier, 2009.

JANNUZZI, P. M. Indicadores Sociais no Brasil: conceitos, fontes de dados e aplicações. Campinas: Editora Alínea, 2004.

MINGOTI, S. A. Análise de dados através de métodos de estatística multivariada. Belo Horizonte: UFMG, 2007.

PEREIRA, R. H. et. al. Análise da dinâmica do desenvolvimento socioeconômico na Amazônia nos anos de 2000 e 2010. Revista de Desenvolvimento Econômico, v. 1, n. 33, p. 251-270, 2016.

RIBEIRO, F. A. N. Parcerias Comunidade-Empresa na Amazônia Brasileira. 2004. 73f. Monografia (Graduação em Economia) - Universidade de São Paulo. São Paulo, 2004.

ROSADO, P. L; ROSSATO, M. V.; LIMA, J. E. Análise do Desenvolvimento Socioeconômico das Microrregiões de Minas Gerais. Revista Econômica do Nordeste, v. 40, n. 02, p. 297-310, Abr./Jun. 2009.

SACHS, I. Ecodesenvolvimento: crescer sem destruir. São Paulo: Vértice, 1986.

SACHS, I. Rumo à Ecossocioeconomia: teoria e prática do desenvolvimento. São Paulo: Cortez, 2007.

SACHS, I. Desenvolvimento: includente, sustentável, sustentado. Rio de Janeiro: Garamond, 2004.

SEN, A. Desenvolvimento como liberdade. São Paulo: Companhia das Letras, 2000. 
SOARES JUNIOR, J. S.; QUINTELLA, R. H. Instrumentalização do desenvolvimento: teorias, conceitos e indicadores. Organizações \& Sociedade, v. 45, p. 61-78, 2008.

SOUZA, A. P. et al. Indicador Social de Desenvolvimento dos Municípios - ISDM. São Paulo: Escola de Economia de São Paulo, FGV, 2012.

SOUZA, E. F. de. Os Polos Agroflorestais como Política de Desenvolvimento Rural Sustentável em Rio Branco no Acre: da proposição à realidade. Viçosa: DED/UFV, 2008. 180p. Dissertação (Mestrado em Economia Doméstica) - Universidade Federal de Viçosa, 2008.

VEIGA, J. E. Desenvolvimento é sinônimo de crescimento econômico? Valor Econômico, São Paulo, 11 mar. 2003. Disponível em: http://www.fea.usp.br/feaecon//media/fck/File/007-2003-03-11.pdf. Acesso em: 10 jan. 2015.

VEIGA, J. E. Desenvolvimento sustentável: o desafio do século XXI. Rio de Janeiro: Ed. Garamond, 2005.

VEIGA, J. E Entender a Sustentabilidade. Valor Econômico, São Paulo, 28 out. 2014. Disponível em: http://www. valor.com.br/. Acesso em: 10 jan. 2015. 